\title{
An Empirical Study on the Linkage Effect between Shanghai Composite Index and Standard \& Poor's 500 Index
}

\author{
Lingyun Luo ${ }^{1, a}$,Chenggang $\mathrm{Li}^{1, \mathrm{~b}} *$ and Jue $\mathrm{Hu}^{2, \mathrm{c}}$ \\ ${ }^{1}$ Faculty of Finance, Guizhou University of Finance and Economics, Guiyang, China \\ ${ }^{2}$ Faculty of Life Science and Chemistry, Hunan University of Technology, Zhuzhou, China \\ ally089@163.com, ${ }^{\mathrm{b}}$ lichenggang603@126.com, ${ }^{\mathrm{C}}$ hujue8116@hotmail.com
}

Keywords: Linkage effect; VAR mode; Impulse response function; Variance decomposition

\begin{abstract}
In this paper, we use the R language to establish the VAR model, select the daily data of the Shanghai Composite Index and the S \& P 500 index from April 5, 2012 to December 24, 2016, and analyze the linkage effect between the two indices through the impulse response and variance decomposition function. The results show that the S \& P 500 index has major lagged impact on the Shanghai Composite Index, while the Shanghai Composite Index has little lagged impact on the $S$ \& P 500 index. The impulse response function results show that the Shanghai index expands its own impulse response stimulus on the S \& P 500 index. The variance decomposition analysis shows that the variance of the forecast error of the Shanghai Composite Index is mainly due to its own time. The S \& P 500 index forecast variance increases with time, and the Shanghai Composite Index occupies an increasing proportion.
\end{abstract}

\section{Introduction}

As the Qualified Foreign Institutional Investors (QFII) quota increased from $\$ 30$ billion to $\$ 80$ billion and further increased to $\$ 150$ billion on April 3, 2012 and July 2015, respectively. RQFII extended from Hong Kong pilot to Singapore, London and other 13 countries and regions, indicating that China's capital market is in an orderly further open. Due to the introduction of Qualified Domestic Institutional Investor system in June 2007, institutional investors can choose to enter the global market on their own initiative. The opening of Shanghai-Hong Kong Stock Connect in 2014 and Shenzhen-Hong Kong Stock Connect in 2016 further opened up the securities market in China. With the growth of China's GDP and people's wealth, China's securities market has ranked the world's second largest market, and the largest turnover rate in the market. Therefore, China's stock market is influenced by other developed countries in the global capital markets.

\section{Literature Review}

In terms of the stock market linkage and volatility spillover effect, China and foreign scholars have done a lot of researches. The world stock markets linkage was first found in 1979 by Hillard. Hillard studied the stock market of 10 countries comparatively, and he used the daily closing price of the stock index from developed countries as data to explore what changes in linkage effect before and after the global financial crisis. He not only examined the correlation between the same period, but also studied the lag correlation, and he concluded that the economic crisis has aggravated the linkage between the various stock markets[1]. The efficient market hypothesis theory of Fama $(1970,1991)$ provides a theoretical basis for the dynamic shock effect caused by the basic factors. He believes that investors are completely rational, and he also assumes that the global economy is integrated, and the financial market is completely open without friction. The existence of arbitrage will inevitably lead to the convergence of income between the securities market [2,3]. In the empirical study, we mainly use cointegration method, Granger causality test, GARCH model, VAR model and Copula function. For foreign scholars' studies, Engle and Granger, a Nobel economist, proposed a cointegration theory in 1987, which mainly argues that there may be a balanced long-term relationship between unsuitable sequences. The emergence of this research method 
provides a theoretical basis for researchers to quantitatively study the linkage between the stock markets and the model [4]. Eun and Shim (1989) used the vector autoregressive (VAR) model to test the linkage effect. They concluded that there was a significant linkage between the markets of each country, and that the US stock market was guided, and the other stock markets followed the changes in the US stock market [5].

Chinese experts and scholars have also carried out a series of studies on this subject. Zewei Liu (2012) used the Granger causality test and the VAR model to select China's A-share index and the US Nasdaq index as the raw data. From China's completion of the share-trading reform to the US financial crisis. The domestic stock market has an impact on the world stock market, and the impact of the world stock market on the domestic stock market is not obvious. The impulse response analysis shows that the information transmission cycle is shortening, and its efficiency is improving [6]. Shengnan Li (2013) established VAR model, using ADF test, Johansen test, Granger causality test, impulse response function and variance decomposition analysis to analyze the linkage relationship between Shanghai Composite Index and the US S \& P 500 Index. The linkage between stock markets can exist a variety of channels, for example, through the real economy transfer to the stock market, through international capital flows driven by the stock market linkage, also the investors' psychological expectations have a significant impact on the stock market[7]. Xi Cheng, Yan Shu (2014) uses the panel VAR analysis to compare the exchange rate, the relative impact of the stock yield on the volatility of the valuation effect, and the dynamic relationship between them. The variance decomposition results show that the volatility of the valuation effect is mainly determined by the portfolio and currency allocation of net foreign currency assets. The volatility of the valuation effect of exchange rate and relative stock yield is much smaller in the emerging market countries than that in the developed market countries. The further analysis uses the impulse response function and found that when the valuation effect was affected by the exchange rate, there was a reversal in emerging market countries. When the relative impact of stock returns will change in the same direction[8]. Yong gang Liu (2015) used the cointegration test, MS-VAR type and impulse response function to link the Shanghai Composite Index and Hong Kong Hang Seng Index. The sample interval is chosen from monthly data from December 1990 to February 2015. The empirical results show that there is a cointegration relationship between the Shanghai Composite Index and the Hong Kong Hang Seng Index in long-term, and the long-term linkage is increasing [9]. Ruijie Yang et al (2015) used the CSI 300 Index and the Hang Seng Index high-frequency data, Barndorff-Nielsen's volatility decomposition model, smoothness test, Granger causality test and VEC model to study the impact of mainland stock market and Hong Kong stock market volatility spillover after Shanghai-Hong Kong Stock Connect opening. It is concluded that there was only a one-way spillover from the Hongkong stock market volatility to the mainland stock market before Shanghai-Hong Kong Stock Connect opening. After Shanghai-Hong Kong Stock Connect opening, there was a two-way spillover from the mainland stock market volatility to the Hongkong stock market volatility[10].

To sum up, many scholars have used VAR model to carry out the linkage effect of the stock market index or dynamic spillover effect. Granger causality analysis has the ability to test the causal relationship, while the impulse response function and the variance decomposition function in the VAR model can be a good simulation of a stock market index suffered another impact on the stock market changes. Therefore, this paper establishes the VAR model to study the relationship between the Shanghai Composite Index and the S \& P 500 Index. And we provide suggestions for policy and personal operation for individual and group participants in China's securities market, as well as policy recommendations for the government to effectively prevent the impact of international market volatility on China's market.

\section{Data Sources and Processing}

Data Sources. This article uses the $\mathrm{R}$ language and getSymbols directive to automatically download data from the Internet. The data used for the Shanghai Composite Index and the S \& P 500 Index was the transaction data from 2012-04-03 to 2016-12-24. 
Data Processing. Take the adjusted closing price of the downloaded data, take the logarithm and then make a difference to get the yield of the day.

Unit Root Test. Use the daftest directive of the $\mathrm{R}$ language to perform a unit root check. The original hypothesis is the existence of unit roots. Detection shows that the $\mathrm{P}$ value is very small, which are about 0.01 . At $5 \%$ confidence, it can be considered that there is no unit root, that is, the Shanghai Composite Index and the S \& P 500 daily returns are stable sequences.

\section{Empirical Analysis}

Determination of Lag Order. Using $\mathrm{R}$ software, the input lag order is set as 22, and the AIC criterion, HQ criterion, SC criterion and FPE criterion are observed from 1 22 degree lag order. R language automatically selects lag order (Table 1).

Table 1 AIC,HQ,SC,FPE Criterion

\begin{tabular}{|l|l|l|l|}
\hline AIC(n) & $\mathrm{HQ}(\mathrm{n})$ & $\mathrm{SC}(\mathrm{n})$ & $\mathrm{FPE}(\mathrm{n})$ \\
\hline 4 & 1 & 1 & 4 \\
\hline
\end{tabular}

Comparing the numerical values of AIC, HQ, SC and FPE, and select the first lag model, which is the VAR (1) model.

Granger Causality Test. Use Granger test function of the latest packet in R for the Granger causality test. The results are shown in Table 2.

Table 2 Granger Causality Test

\begin{tabular}{|l|l|}
\hline Model & P value \\
\hline Model 1: r.GSPC Lags(r.GSPC, 1:1) + Lags(r.SSEC, 1:1) & 0.607 \\
Model 2: r.GSPC $~$ Lags(r.GSPC, 1:1) & \\
\hline Model 1: r.SSEC Lags(r.SSEC, 1:1) + Lags(r.GSPC, 1:1) & $1.478 \mathrm{e}-08$ \\
Model 2: r.SSEC Lags(r.SSEC, 1:1) & \\
\hline
\end{tabular}

From Table 2, we can conclude that, under $1 \%$ significance level, the S \& P 500 is not the Granger reason of the Shanghai Composite Index as the $\mathrm{P}$ value is too large to reach 0.607; while the Shanghai Composite Index is the Granger reason of the S \& P 500 because the P value is $1.478 \mathrm{e}-08$.

Model Establishment. Use the R language directive to create a VAR (1) model. SSEC is the daily return rate of Shanghai Composite Index. GSPC is the daily return rate of S \& P 500 Index.

$S S E C=$ SSEC.l1+GSPC.l1+const+trend

Table 3 SSEC Coefficient

\begin{tabular}{|l|l|l|l|}
\hline SSEC.11 & GSPC.11 & const & trend \\
\hline 0.027680770 & 0.312813107 & -0.010335625 & 0.000044017 \\
\hline
\end{tabular}

$G S P C=S S E C . l 1+\mathrm{GSPC} . l 1+$ const+trend

Table 4 GSPC coefficient

\begin{tabular}{|l|l|l|l|}
\hline SSEC.11 & GSPC.11 & const & trend \\
\hline-0.005541743 & 0.010428999 & 0.059339842 & -0.000026227 \\
\hline
\end{tabular}

From the model we can find out that the Shanghai Composite Index is mainly affected by the lag first order of S \& P 500 Index, and the coefficient is 0.3128 . Meanwhile, the S \& P index was significantly affected by its self-lag first-order, and the self-lag first-order coefficient is 0.02768 . 
The model shows that the impact coefficient of the first index of the Shanghai Composite Index is -0.005541743 , indicating that the impact of the Shanghai Composite Index on the S \& P is reverse and minimal.

Impulse Response Analysis. R language impulse response function instructions was used for analysis, the results are shown in Figure 1.

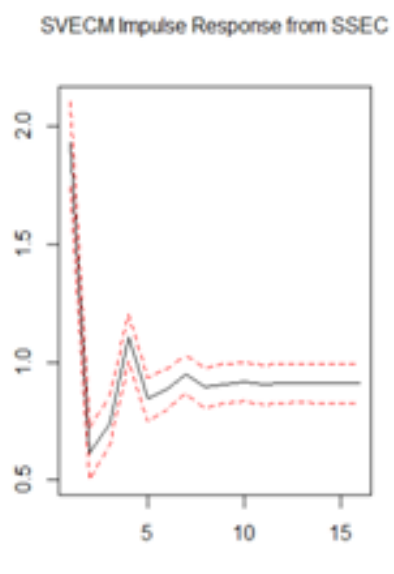

$95 \%$ Bootstrap C, 100 nums

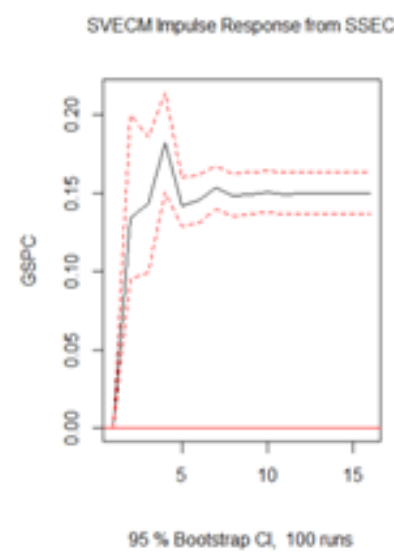

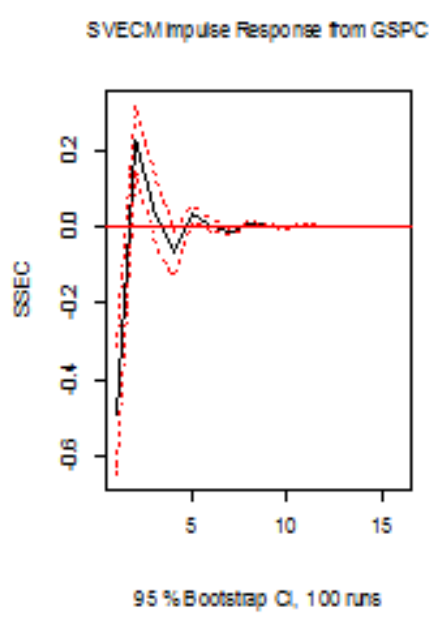

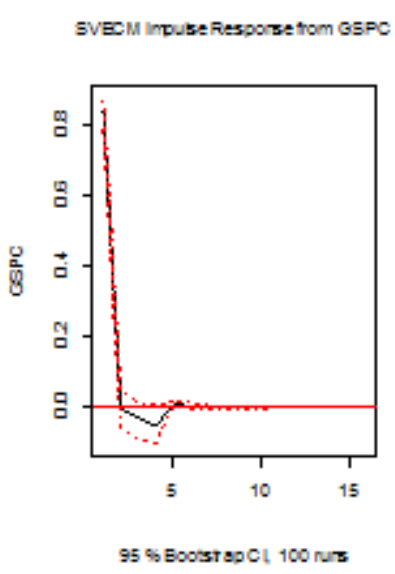

Figure 1 Impulse Response

As shown in Figure 1, the Shanghai stock index is given a current standard deviation of the Shanghai Composite Index impulse response shock. The Shanghai Composite Index fluctuates in a short term, for instance, on the first day the index was 2.0, while on the second day it quickly dropped to 0.6 , and it gradually increased to 1.2 and then quickly returned to 0.8 on the fourth day and the fifth day respectively. Finally the index reached a stable and normal state of around 0.95 on seventh to the eighth day. After giving the impulse response, the Shanghai Stock Exchange index had changed greatly in the short term and been stable in the long-term period.

Giving a current standard deviation of the S\&P 500 Index impulse response shock to the Shanghai stock index. Results showed that, the index changed from -0.5 to 0.2 from the first day to the next day, then fell to -0.1 on the fourth day, and rose to 0.05 on the sixth day. Finally, the Shanghai index backed to a normal state of 0 and remained stable on the seventh to the eighth day. As discussed above, the Shanghai index suffered a pulse impact in the short-term, but the impact subsided in the long-term, which was around 0.

After giving the S\&P 500 Index a current standard deviation of the Shanghai Stock Index impulse response shock. The $\mathrm{S} \& \mathrm{P}$ index remained unchanged in the first phase, but increased to 0.13 in the second period. The index then continued increasing to 0.18 in the third and fourth 
periods, in which the index reached a peak in the fourth period, however, it dropped to 0.14 in the fifth period, then increased to 0.15 in the sixth period and fluctuated around 0.15 for several periods, and finally it stabilized at 0.15 .

Giving a current standard deviation of the S\&P 500 Index impulse response shock to itself. The reaction in the first phase is intense, which is 0.85 , and then it gradually decreased to 0 in the second period, and down to -0.1 in the third phase to the fourth period, finally, it recovered to around 0 in the fifth period and remained stable.

Variance Decomposition. As shown in Fig. 2, R language was used for variance analysis.

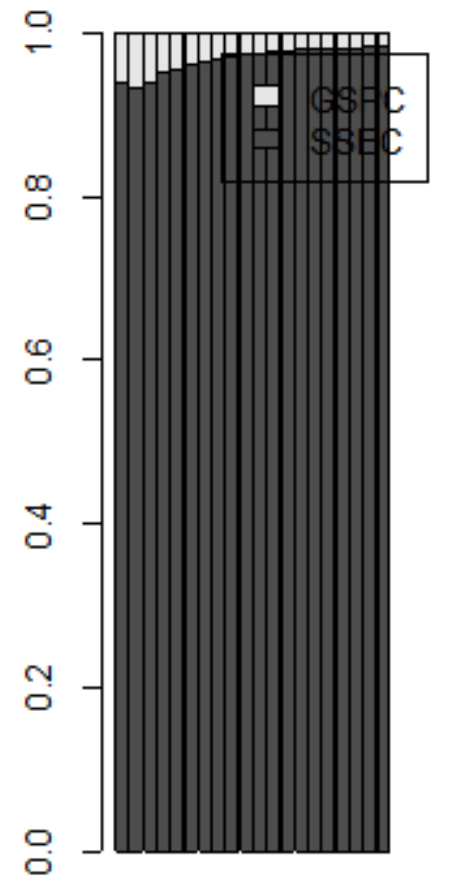

$\begin{array}{lllll}1 & 5 & 9 & 14 & 19\end{array}$

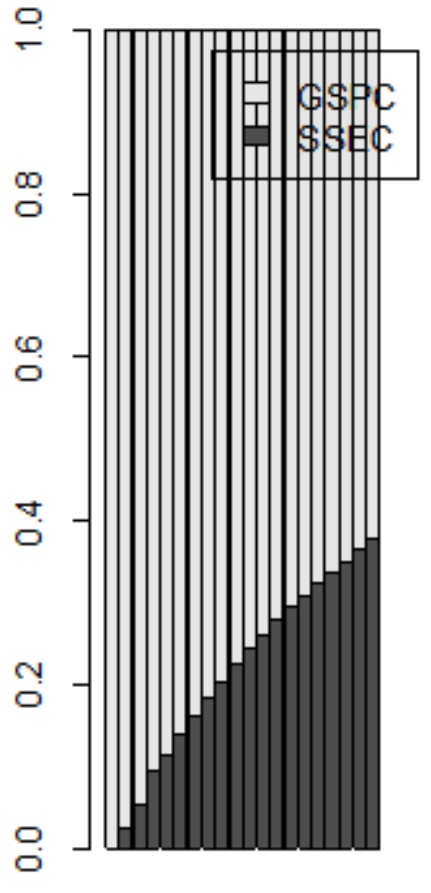

$\begin{array}{lllll}1 & 5 & 9 & 14 & 19\end{array}$

Figure 2 Variance Decomposition

The variance decomposition is to decompose the mean square error predicted by the system to explain the contribution of the random impact of each variable and to show the importance of each variable. From the variance decomposition diagram of Figure 2, we can conclude that the Shanghai stock index forecast variance is mainly affected by its own. The contribution of the Standard \& Poor's index is quite large in the first phase, and becomes larger in the second phase, after that it decreases gradually. The predictive variance of the S \& P 500 is also mainly affected by its own. However, as time goes on, the variance decomposition shows that the Shanghai Composite Index contributes more and more to the variance of the S \& P 500 index. The influence of the Shanghai Composite Index on the S \& P index variance is increased from the initial 0 to about 0.4 in the 20 periods.

\section{Conclusion and Policy Suggestion}

In this paper, the VAR model is used to analyze the linkage effect between the Shanghai Composite Index and the S \& P 500 Index. The empirical analysis shows that the S \& P 500 Index has a greater impact on the Shanghai Composite Index, while the Shanghai Composite Index has a negative impact on the S \& P 500 Index and its influence is quite small. The impulse response function is concluded as follows:(a) The Shanghai Composite Index impulse response has more significant impact on the Shanghai Composite Index in the short-term, and the long-term impact tends to be stable at around 1; (b) The impact of the $\mathrm{S} \& \mathrm{P}$ Index impulse response has a short-term impact on 
the Shanghai Composite Index, but the impact is minor, and the long-term trend of it is 0; (c) The Standard \& Poor's 500 Index pulse has a huge short-term impact on the S \& P 500 Index and with a long-term trend of around 0; (d) The impact of the Shanghai index on the S \& P 500 was much more in the short-term, while its impact decreased in the long-term and reached stable in 0.15. Variance analysis shows that, over time, the Shanghai Composite Index forecast variance mainly from their own. The S \& P 500 Index forecast variance is also mainly on their own, but as time goes by, the Shanghai index accounted for more and more.

Accoding the above conclusions, we can come up with the following policy recommendations: (a) The S \& P 500 Index has a positive impact on the Shanghai Composite Index. Chinese institutional investors and retail investors can focus on the yield of the US stock market in the previous day, which can provide a reference to the second-day investment strategy. (b) From the impulse response analysis, it can be seen that the short-term fluctuation in the American market will lead to a sharp fluctuation in our domestic market. Regulators should pay close attention to the market in the recent volatility of the US market and develop countermeasures to reduce the impact of US market volatility on the domestic market.

\section{References}

[1] J.E. Hilliard, The Relationship Between Equity Indices on World Exchanges, The Journal of Finance. 34 (1979) 103-114.

[2] E.F. Fama, Efficient Capital Markets: A Review of Theory and Empirical Work, The Journal of Finance. 25 (1970) 383-417.

[3] E.F. Fama, K.R. French, Common risk factors in the returns on stocks and bonds, The Journal of Finance. 33 (1993) 3-56.

[4] R.F. Engle, C.W.J. Granger, Co-integration and Error Correction: Representation, Estimation, and Testing, Econometrica. 55 (1987) 251-276.

[5] C.S. Eun, S. Shim, International Transmission of Stock Market Movements, Journal of Financial and Quantitative Analysis. 24 (1989) 241-256.

[6] Z. Liu, An analysis of the linkage effects between China's stock market and the world's major stock markets, Southwestern University of Finance and Economics, Chengdu, China, 2012.

[7] S. Li, A study of the linkage between Chinese stock market and US stock market, Suzhou University, Suzhou, China, 2013.

[8] X. Cheng, Y. Shu, Volatility of valuation effects: an analysis based on panel VAR Studies of International Finance 5 (2014) 88-96.

[9] Y. Liu, Analysis on the Linkage between Shanghai Composite Index and Hong Kong Hang Seng Index, Dongbei University of Finance and Economics, Dalian, China, 2015.

[10] R. Yang, X. Zhang, The impact of opening of Shanghai-Hong Kong Stock Connect on volatility spillover of mainland and Hongkong stock markets, Journal of Guangdong University of Finance. 6 (2015) 49-59. 